\title{
A VOXEL-BASED METHOD TO ESTIMATE NEAR-SURFACE AND ELEVATED FUEL FROM DENSE LIDAR POINT CLOUD FOR HAZARD REDUCTION BURNING
}

\author{
J. Barton*, B. Gorte, M. S. R. S. Eusuf, S. Zlatanova \\ Geospatial Research, Innovation and Development (GRID), Built Environment, UNSW, Sydney, Australia \\ (jack.barton, b.gorte, m.eusuf, s.zlatanova)@unsw.edu.au
}

Commission IV

KEY WORDS: Bushfire Fuel, LiDAR, Voxels, Hazard Reduction Burning, Disaster Mitigation, J software

\begin{abstract}
:
Drastic changes in the climate has revised the face of disaster management: it is contributing to abnormal intensity, frequency and duration of extreme weather and climate events. The year 2020 started with more than 100 fires burning across Australia. Hazard reduction burning has become a resolute and primary land management technique that contribute to the reduction of bushfire severity. One of the key variables to consider for this application is fuel load, as the accumulation of vegetation in a forest profile affects the intensity of the burn. Conventionally, fuel loads are measured by manually cutting the vegetation and physically measuring the quantity after dry heating. This process is expensive, and time consuming. There is an opportunity for these techniques to be digitised and automated to give results in a timely manner and work as a decision support tool for practitioners. This paper proposes a voxel-based approach that can be used for estimating fuel load and percentage cover of the vegetation, at the elevated and near-surface fuel/vegetation layer as a method to augment manual estimation. We use an airborne LiDAR pointcloud dataset of Vermont Place Park, Newcastle, Australia to test the method. The preliminary inspection of the results confirms the technique that can approximate conventional manual method. Next steps include performance testing including more dataset to derive quantitative measures on the approach.
\end{abstract}

\section{INTRODUCTION}

Australia has an extensive history with bushfire, with charcoal and fossil deposits indicating the presence of wildfire as far back as 400,000 years ago (Vigilante and Thornton 2016). Australia is known for its extreme weather events, however climate change is making these events increasingly severe (Steffen et al. 2019). The $2019 / 2020$ bushfires have been dubbed as one of the worst bushfire seasons in Australia, burning more than 2 million hectares of land in New South Wales (NSW) and Queensland alone (Chang 2020). From 1967 until 2013, bushfires have cost the Australian economy 4.7 billion dollars (Handmer et al. 2018). Along with the loss of human lives and damage to the built environment, natural habitats of native species have been severely impacted, conditions made favourable for invasive species and the air quality is also affected, as illustrated in Figure 1.

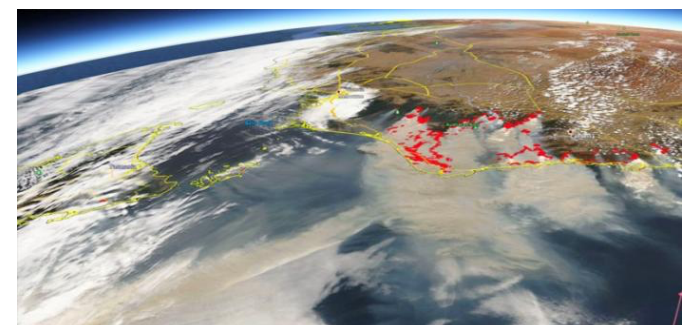

Figure 1: Smoke rising from fires on the east coast of Australia, red shows live fire (Vernier and Reed 2020).

Climate condition, topographic features, fuel/vegetation condition and its accumulation are the factors that contribute to bushfire behaviour (Gould and Cruz 2012). Increasing temperature from global warming has prompted the worlds climate to change abruptly, making hot days hotter. Resulting in dryer vegetation, drier the vegetation the faster the fuel will ignite. Hazard reduction (HR) burning is a technique that is commonly used by fire practitioners worldwide, it is also known as controlled burning, prescribed burning, backfire, swailing or burn-off (Gage 2016). Its application is by deliberately reducing accumulated vegetation through direct burning in bushfire prone areas. In Australia, HR burns are conducted based on several guides, each state has its own guide to assess fuel. Commonly used guide in New South Wales (NSW) are the Overall Fuel Hazard Assessment Guide (OFHAG) and Knee-waist-shoulder Estimation Guideline (Hines, et al. 2010, Forestry Commission of Tasmania, 1984).

OFHAG outlines a hazard rating from low to extreme for vegetation layers in a forest profile. One of the metrics used to assess hazard rating is Fuel Load (FL) - the accumulation of vegetation over an area (Volkova et al. 2016). FL is considered along with weather and topography when conducting hazard reduction burning (Penman et al. 2011). There are two conventional method for acquiring FL data, common attribute of both the techniques are that the fire practitioner will go to the dense forest profile and visually assess at what location has the highest accumulation of vegetation. The difference between the two is that: 1) Deliberately cuts the vegetation of interest, oven dries it and weigh the vegetation. 2) Fire practitioner goes to the site and assess the vegetation based on plant percentage cover and surface litter depth, at a certain radius around the assessor. Both of this technique are time consuming and costly. At the same time, this visually assessments are prone to errors due to the technique's subjectivity of the assessment (Volkova et al. 2016, Spits et al. 2017). It has been predicted that by 2050 the number of very high and extreme fire days will increase by $15-70 \%$ (Hennessey et al. 2005, The Australia Institute 2007). That is why automating the process of acquiring FL data could give faster and reliable data to make tactful decisions when conducting HR

\footnotetext{
${ }^{*}$ Corresponding author
} 
burns. Remote sensing technologies enable the collection of spatial data to facilitate fuel classification and analysis (Dubayah and Drake 2000, Skowronski et al. 2011, Hermosilla et al. 2014, Chen, Zhu et al. 2016). Light Detection and Ranging (LiDAR) facilitate rapid acquisition of detailed data and allow tasks to be increasingly digitised and automated (Yebra et al. 2015, Price and Gordon 2016). LiDAR has been widely used worldwide for classifying forestry characteristics. In Turkey (Inan et al. 2017) investigated the potential of airborne lidar to characterise the forest profile based on: tree height, tree diameter, crown diameter and the tree volume. This research quantified the forest stands (trees) in a forest profile. (Almeida et al. 2016) used a portable profiling LiDAR for fire susceptibility and contrasting fire damage in the central Amazon. To determine the individuality of trees from colour pointcloud data. However, both this research did not fully explore the potential of LiDAR.

Gorte and Winterhalder (2004) and Thies et al (2004) reported a voxel-based approach using mathematical morphology, skeletonization, connected component labelling and shortest path computation to reconstruct $3 \mathrm{D}$ trees from terrestrial scans. Hermosilla, Ruiz et al. (2013) in USA, Spain and Canada developed a methodology for the estimating the forest structure and canopy fuel parameters. They developed metrices for input variables for predictive fire models using forward stepwise multiple linear regression. This study used small- footprint and large-footprint full-waveform LiDAR sensors that collected data for over a decade. They used two approaches to answer the limitation present from full-waveform data (unable to detect detailed structure of the forest) (Listopad et al. 2012): Pulse detection and waveform modelling (Mallet and Bretar 2009). Similar approaches were used in different ecological areas in USA to quantify forest structures and species (Riano et al.2004, Skowronski et al. 2011, Zhao et al. 2011, Gonza' lez-Olabarria et al. 2012). In Canada and France, Grau et al. (2017) estimated 3D vegetation data with terrestrial laser scanner data using voxels based approach. They used ray tracing method to simulate realistic TLS data acquisition, then simulated realistic vegetation scene from a 3D range of plant area index (PAI) distribution and calculated voxel area density. This research evaluated the potential of voxels, and lead to the development of a tool called VoxelSD. This tool can be used to assess $3 \mathrm{D}$ vegetation density from TLS scans. It is an innovative way to estimate the distribution of plant/ leaf area with accuracy.

Over 60 years of extensive research, Australia has demonstrated several systems that could model and predict fire behaviour (Gould and Cruz 2012): CSIRO Grassland fire spread meter (Cheney et al. 1998; Cruz et al. 2015b), Phoenix Rapid Fire (Tolhurst and Chong, 2008) and the oldest model being the McArthur (1967). One of the common variables needed for this system is the FL data. (Chen et al. 2016) developed two predictive models of forest surface fuel load based on: LiDAR indices, forest types and previous fire disturbances. They classified the forest fuel structural characteristics based on surface fuel depth and percentage cover at distinct layer using a Terrestrial Laser Scanner (TLS): they classified the fuel using a raster image of a surface fuel depth that is interpolated based on the TLS points height values (h) at surface fuel layer. They then generated a scatter diagram for forest vertical profiles by plotting the density of LiDAR points against height and used a bimodal distribution to identify LiDAR points. Two models were created: $1^{\text {st }}$ represents the density distribution of LiDAR points across vertical profile of understorey shrubs and the $2^{\text {nd }}$ component plots the density distribution in overstorey fuel. Locally weighted scatterplot smoothing (LOWESS) was applied to smoothen the scatter plot. Two models were compared and the cut point between the two components of the bimodal curve was utilized to stratify and characterise the vertical structure of the forest and derive LiDAR indices for different vegetation layers. This LiDAR derived stratification method provides a significant contribution in vegetation classification, forest habitat mapping as well as forest wildlife conservation. (Spits et al. 2017) investigated the surface and near-surface bushfire attributes from Image-based point clouds. The image-based point cloud was captured from smart phones loaded with Fuels3D application. Fuels3D application is a tool for measuring fuel hazard and fire severity in the forest understorey (op.cit).

Most studies done to characterise forest fuel are attributed to the canopy layer of the forest profile, understandable as its responsible for the rate of fire spread and severity (Gould, McCaw et al. 2011, Gould and Cruz 2012, Chen et al. 2016, Price and Gordon 2016, Spits et al. 2017). However, there are limited studies done in the understorey of the vegetation layer. In this paper, we propose a voxel-based approach to estimate the volume of fuel in near-surface and elevated fuel layers below the canopy. Voxelisation is a useful spatial analysis technique when applied to dynamic phenomena like wind, fire, air and noise pollution (Gorte and Zlatanova, 2016). This approach may assist in quantifying FL from pointcloud data by building a threedimensional image of the composition of the forest. The next section provides an overview of HR burning and explains the methods to quantify fuel load; then the paper elaborates on the voxel-based methodology to estimate the volume of surface and elevated FL. The paper concludes with proposed future research and development.

\section{PROCEDURE FOR FUEL ESTIMATION}

\subsection{Fuel Classification}

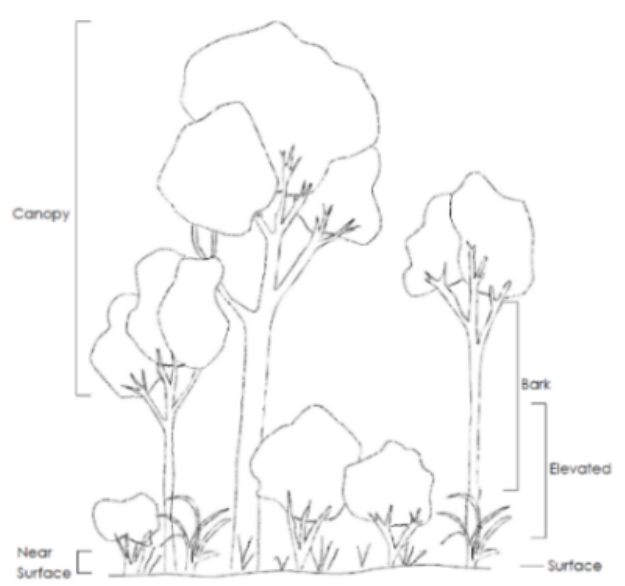

Figure 2: The key structural layers of the fine fuel complex (Hines et al. 2010).

Fuel can be classified based on five structural layers in the forest: canopy fuel, bark fuel, elevated fuel, surface fuel, near-surface fuel, as illustrated in Figure 2. At the canopy layer, leaves and twigs are usually found on the tallest layer of the forest or woodland. The canopy is included in the elevated fuel. Bark fuel is the flammable bark on tree trunks and upper branches. Elevated fuel shrubs and juvenile understorey plants are usually $2-3 \mathrm{~m}$ in height. Near-surface fuel are grasses, low shrubs and heath, these often have suspended components like leaves, barks and twigs (Hines et al. 2010 


\subsection{Assessing Fuel Load}

The conventional way to assess FL in NSW is based on the kneewaist-shoulder estimation from the HR burning under dry forests guideline (Forestry Commission of Tasmania, 1984) as illustrated in Figure 3. This guide estimates FL using a visual assessment of surface fuel. A fire practitioner will go to the site, locate a spot and visualise at $2 \mathrm{~m}$ radius (or $10 \mathrm{~m}$ radius) around the assessor and then estimate the surface litter depth of fuel that is $<6 \mathrm{~mm}$ in diameter. Once the surface litter is established it is then correlated with the percentage of plant cover in that $2 \mathrm{~m}$ radius circle. The combination of the litter depth and plant coverage provides an estimate for FL.

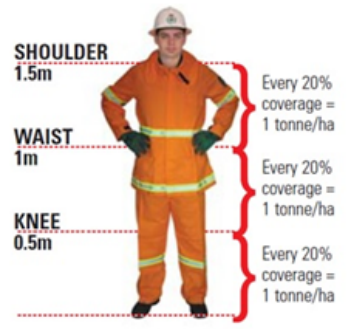

Figure 3: Knee-waist-shoulder estimation guidelines for HR Burning (Forestry Commission of Tasmania, 1984).

Figure 4 shows how FL is estimated and assessed by the fire practitioner. FL is estimated based on three segments. First the ground to knee (at $0.5 \mathrm{~m}$ ), knee to waist (at $1 \mathrm{~m}$ ) and then waist to shoulder $(1.5 \mathrm{~m})$. These three segments are later added based on the percentage of plant coverage, to give the estimated total fine fuel. Figure 4 illustrates how plant cover percentages are mapped while looking straight down at the forest profile from the above (Spits et al. 2017, Hines et al. 2010).

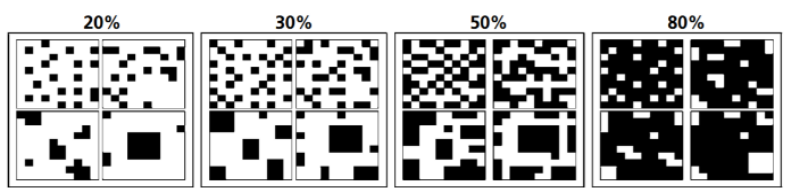

Figure 4: Visual guide for assessing plant cover (Hines et al., 2010).

The percentage coverage of plant matter is used to estimate FL. For every $10 \%$ of cover at $20 \mathrm{~mm}$ surface litter depth approximates to $1 \mathrm{t} / \mathrm{ha}$, for every $100 \%$ at $20 \mathrm{~mm}$ surface litter approximates to $10 \mathrm{t} / \mathrm{ha}$. If the plant coverage seems less than $100 \%$, then the percentage cover needs to be lowered to $80 \%$ then the estimated FL would be $8 \mathrm{t} / \mathrm{ha}$ (Forestry Commission of Tasmania, 1984).

\subsection{Fuel Hazard rating}

The resulting FL estimates are converted to surface fuel hazard scores as low, moderate, high, very high and extreme for the area of interest. At coverage less than $10 \%$, the hazard is considered low as it has no effect to fire behaviour. At $10 \%$ to $20 \%$ it is considered moderate hazard rating as it dictates the flame height. Greater than $20 \%$ onwards the hazard rating is very high and significantly contributes to the flame height and rate of spread of fire. Assessing fuel hazard rating at the elevated surface fuel level is slightly different from near-surface fuel. Below $20 \%$ fuel coverage it is considered low. From $20 \%$ to $30 \%$ it is considered moderate. At $30 \%$ to $50 \%$ is considered high. HR burning is required for elevated surface fuel after the plant coverage reaches $30 \%$. The near-surface fuel is of high significance when conducting HR burning because when fire spreads, that layer will work as ladder for fire to travel to the other layers in the forest profile (Spits et al. 2017).

These concepts, dynamics and calculations are naturally volumetric and typically deal with small-scale measurements in relation to larger areas of bushland. The ability to gather data remotely and process these data volumetrically and quickly offers the capacity to augment and extend existing techniques and provides an avenue for rapid data collection and analysis to assist in mitigating potential disasters, and pre-planning HR burns that may be quickly executed given the constricted timeframes HR burning is possible.

To assess and manage bushfire risk, planning fuel treatment and controlling smoke plumes, it is crucial to measure the fuel load and its arrangement to inform a versatile range of fire management activities (Zhou et al. 1998, Bradstock et al. 2010, Gould and Cruz 2012, Duff et al. 2017).

Miscalculation of FL can lead to inaccurate data and can therefore have significant management implications. Underestimating FL leads to erroneously eliminating areas in need of HR burning and potentially leaves stakeholders underprepared in the event of a wildfire. Overestimating leads burning where its unrequired; this has environmental, cost and logistical implications. Inconsistent and inaccurate estimation of fuel load could lead to unreliable data for smoke dispersion models, prediction of greenhouse gas emissions and fire line intensity. Accurate and consistent fuel hazard data is imperative for fire and land managers in their decision-making process for fire management practices.

This research focuses on automating the process of measuring FL for HR burning though a voxel-based approach using airborne LiDAR pointcloud data as input.

\section{DATASETS AND VOXELIZATION}

\subsection{Study area, dataset and software}

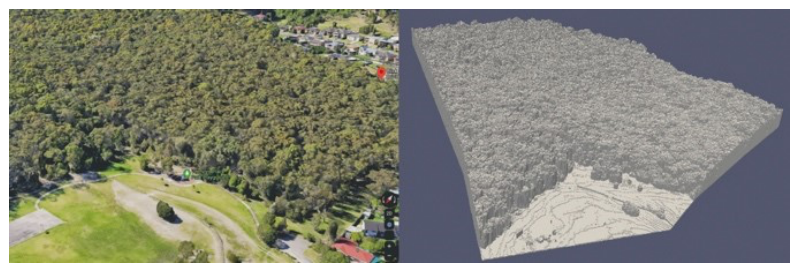

Figure 5: Study area as visualised in Google Earth (left) and voxelised point cloud (right).

The methodology was applied to a dataset representative of typical Australian bushland, obtained from Fire and Rescue NSW. The study area shown in Figure 5 is Vermont Place Park, Newcastle, NSW. The Airborne LiDAR pointcloud is collected by a low altitude drone platform and has an absolute accuracy of $<50 \mathrm{~mm}$ RMSE at 50m range, with 3 returns, an RMS ranging error of $30 \mathrm{~mm}$ and a scan rate of 4201 points/s (1 return). Figure 6 illustrates the test data set.

The pointcloud was transformed into local coordinate system, by truncating the geographical coordinates with the minimum values for $\mathrm{x}, \mathrm{y}, \mathrm{z}$. A voxel grid was then generated across the workspace. Processing in voxel space brings three major advantages to pointcloud space: first, the size of the data to be processed can be reduced significantly; second, the voxel space allows to establish connectivity horizontally and vertically, which facilitates analysis and third, the effect of different point density can be 
reduced, which will be favourable for fuel estimation. High point density from overlapping flights (Figure 7) may give the wrong indication of a higher vegetation density.

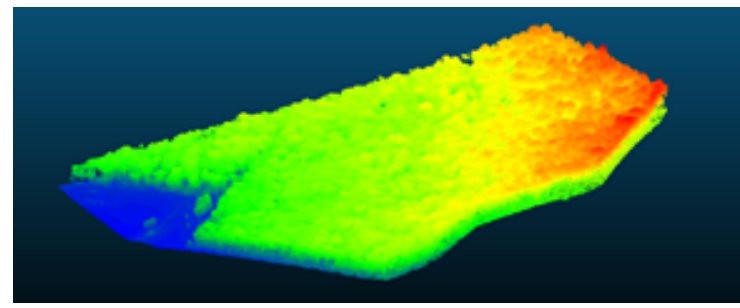

Figure 6: LiDAR pointcloud data. Colour indicates height from $0 \mathrm{~m}$ to $40 \mathrm{~m}$ (blue to red).

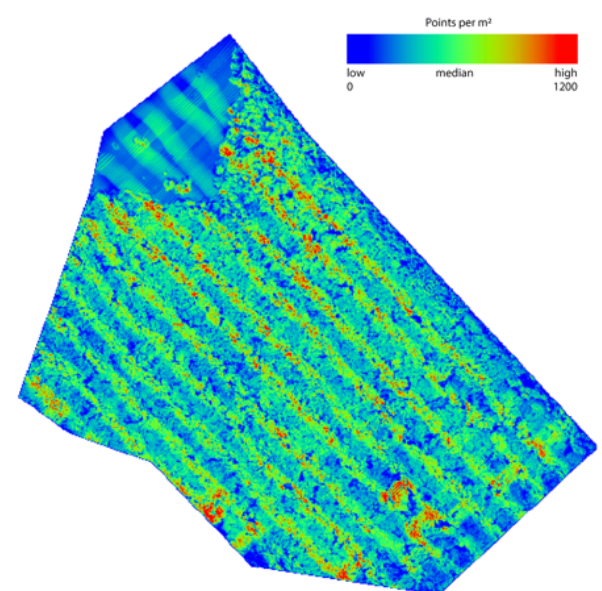

Figure 7: Plot of LiDAR point densities (points $/ \mathrm{m}^{2}$ ).

Figure 7Error! Reference source not found. plots the point densities of the point cloud across the study area. In this visualisation, each pixel is $1 \mathrm{~m}^{2}$ and the densities shown represent the number of LiDAR points at each vertical column. The total number of pixels $/$ samples $/ \mathrm{m}^{2}$ is $\mathrm{n}=127,706$. The diagonal striations reflect the flight path of the airborne LiDAR acquisition unit; the heavier densities are the result of matter receiving two passes of the scanner from a return path, and the lighter areas have only been revealed by one pass. Figure 8 shows the distribution of the point density classes. The most frequent class $300-400$ points $/ \mathrm{m}^{2}$ (Figure 8 ). This suggests the point density within each cell is sufficient for modelling and analysis.

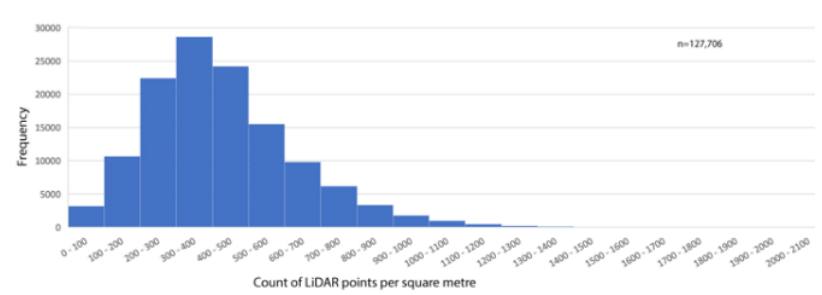

Figure 8: Frequency by number of LiDAR points $/ \mathrm{m}^{2}$.

The voxel analyses are performed with in-house J-based software. $\mathrm{J}$ is a powerful general-purpose array-based language that is suitable to develop algorithms for exploring problems with matrices and higher dimensional arrays. $\mathrm{J}$ is suitable for this study as a voxel space is a typical example of large array. Alongside J, Cloud Compare is used to visually inspect the pointcloud data.

\subsection{Voxel resolution}

The resolution of the voxel space will influence whether voxels are empty or filled as seen in Figure 9. Since we are using the count of non-zero voxels to estimate the fuel load, the resolution of the voxel space is very important. If the resolution is too course, FL is overestimated, if the resolution is too fine, there is a processing and speed overhead.

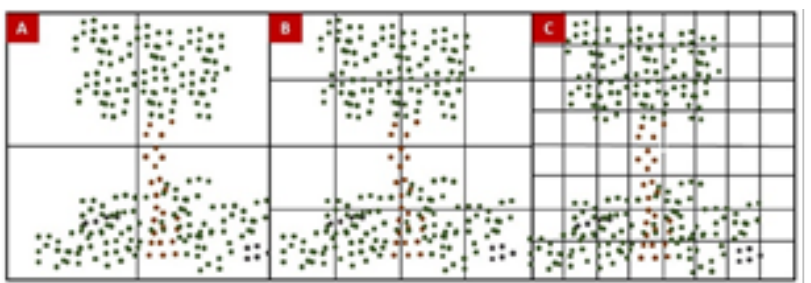

Figure 9: Significance of voxel resolution for the number of non-empty voxels.

Figure 9 shows a 2D representation of a voxel space: A illustrates that all cells are non-empty; higher resolution as in $\mathrm{B}$ has 16 cells non-empty and one empty, $C$ illustrates 21 empty cells if the resolution is four times finer. Given the FL assessment used a dimension of $0.50 \mathrm{~m}$ to knee height, a voxel resolution of $0.40 \mathrm{~m}$ was determined to be optimal in that it each structural fuel layer could be classified as belonging to a particular stratum of voxels and subdivided accordingly.

\section{VOXEL SPACE ANALYSES}

The workflow consists of the following five steps:

1. Terrain estimation

2. Canopy classification and removal

3. Tree trunk classification and removal

4. Near - surface and elevated fuel segregation

5. Estimation of percentage coverage for elevated and near-surface fuel to calculate hazard rating

The dataset for this research has more than the required standard for enabling detailed mapping of the forest profile: however, the density of pointcloud is also variable across the forest profile. Therefore, a voxel-based approach provides an optimal solution to add consistency and operability across low to high point densities (Thies et al 2004).

\subsection{Terrain}

When generating the digital terrain model, a common problem associated with LiDAR scanning of large forest profiles is its inability to penetrate foliage, which occludes the laser beam. This results in incomplete coverages on the understorey of the forest profile. The quality of the digital terrain is critical and influences the following steps. The terrain is determined in the pointcloud through square grid, subdivided into tiles of $4 \mathrm{~m} \times 4 \mathrm{~m}$. The lowest point in those tiles are located and a Triangular Irregular Network (TIN) are created from it, at each tile. Larger tile has a higher probability to have terrain points and the triangulation will approximate the terrain shape. However, the triangulation may lead to omission of hills and gaps. Voxel space is then created above the normalised TIN.

The digital terrain model is then modified so that the ground level and normalised to a horizontal plane, enabling the structural layers to be easily separated according to their relative height above ground level. To normalise the height data, the lowest nonzero voxel in each vertical column is transformed to $\mathrm{z}=0$ (Eusuf 
et al 2020). After the terrain is normalised, we proceed to classify the other components of the forest profile; canopy, tree trunks, elevated surface fuel and near-surface fuel.

\subsection{Canopy classification}

Canopy classification assumes the crowns of the trees form a high-density region of filled voxels in the voxelised point cloud. The determination of this region is based on applying $3 \mathrm{D}$ mathematical morphology operations Dilation and Erosion in a mixture of object and background voxels, where an object is defined as collection of adjacent object voxels.

- Dilation makes objects larger by changing background pixels adjacent to the object into object pixels; holes inside objects and cracks between objects may therefore disappear, i.e. become part of the object.

- Erosion makes objects smaller by turning object voxels near to the outer boundary of an object into background; holes become larger; cracks become wider, small or narrow objects may disappear.

Whether a background voxel is close to an object, resp. an object pixel is close to the boundary (i.e. the background) is determined by the Structuring Element (SE). In this study we use a simple SE that only considers nearest-neighbouring voxels.

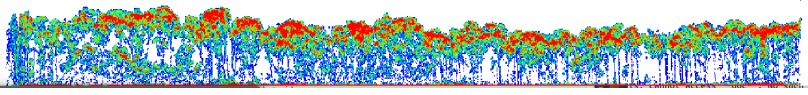

Figure 10: Voxelised point cloud

Starting from the voxelised point cloud (Figure 10) we first apply two iterations of dilations, which adds a layer of $0.80 \mathrm{~m}$ around all objects in that space. As a result, holes of up to $1.60 \mathrm{~m}$ diameter with the canopy region get completely filled up. Also, the top of the canopy becomes $0.80 \mathrm{~m}$ higher, and its bottom $0.80 \mathrm{~m}$ lower. Other objects, such as trunks and understory objects will extend by $0.80 \mathrm{~m}$ in all directions, but some space between these objects will remain. The terrain surfaces become $0.80 \mathrm{~m}$ higher. Next, we apply four iterations of Erosion. This will make originally small objects, even though they had just been extended, completely disappear. However, the (now filled) block of canopy will shrink (by $1.60 \mathrm{~m}$ from all sides), but the core remains.

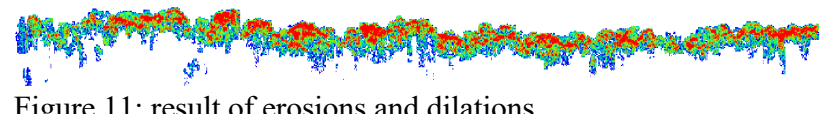

Finally, we apply again two iterations of Dilation. Now the canopy will grow back to its original size, but the objects that had disappeared before will not come back (Figure 11).

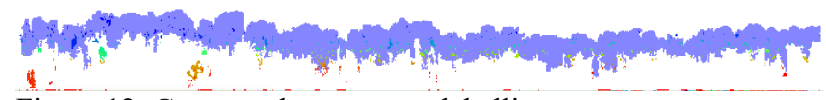

Figure 12: Connected component labelling

To the result of the above we now apply Connected Component Labelling. This operation assigns a unique label (as the voxel value) to each collection of adjacent object voxels, i.e. to each object. After this, the size of each object (i.e. the number of voxels in it) can be easily established from a histogram, and only the very large objects remain as canopy (Figure 12).

\subsection{Tree trunk classification}

The tree trunks naturally cut vertically through the voxel space, through the near-surface and elevated surface fuel and up to support the canopy. For this study, the trunks would have resulted in overestimation of data when calculating the voxel volume of near-surface and elevated fuel. An in-house routine identifies vertically contiguous voxel columns assuming they approximate tree trunks; if there is a large enough connected group of filled voxels, we expect this to be typical of a trunk. The routine looks for groups of 10 vertical voxels with at least 9 filled. If there is a gap, it is considered to be an artefact of occlusion. This set of voxels was then isolated from the dataset. Figure 13 shows the forest profile in a section of the voxels space having width of 10 voxels. The mid graphics shows the isolated tree trunks, and the lower shows just the remaining voxels. They can be considered vegetation that have to be assessed of fuel volume. The colour coding shows red to blue: red representing the more non-empty voxel in the section and blue as the less non-empty voxels.

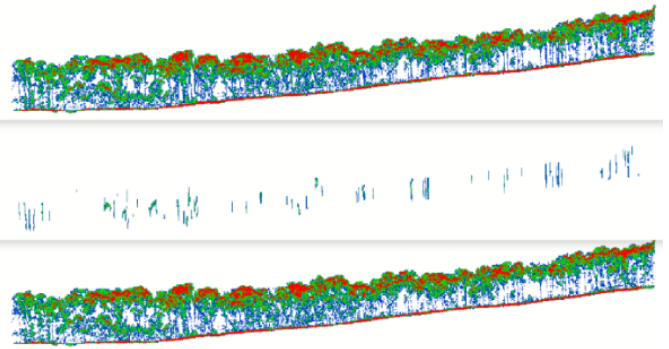

Figure 13: Side elevation showing site before trunk removal (upper), extracted trunks (mid) and vegetation with trunks removed (lower).

Figure 14 shows an oblique aerial view of the entire site and the volume to tree trunk removed from the dataset, and a detail of the trunks showing the voxelised structure of the volumes at $0.40 \mathrm{~m}$ per voxel.

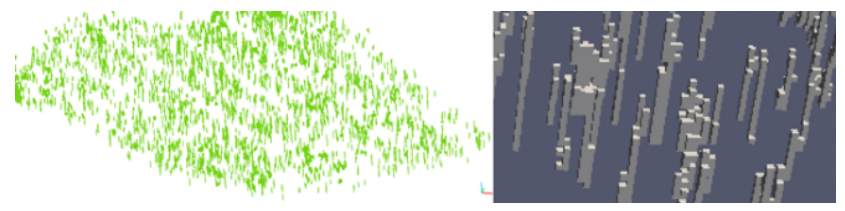

Figure 14: Extracted trunks (left) and detail showing voxels (right).

\subsection{Elevated surface and near-surface fuel}

Having removed everything but the structural layers of elevated surface fuel and near-surface fuel, the two layers can be further analysed to estimate the amount of undergrowth of vegetation at each level. It is important to state that the lowest voxel in each column represents the ground plane- having no LiDAR points below the ground level. This is voxel zero. At a resolution of $0.40 \mathrm{~m}$, voxel 1 and voxel 2 represent near-surface fuel and elevated surface is upward from voxel 3. 


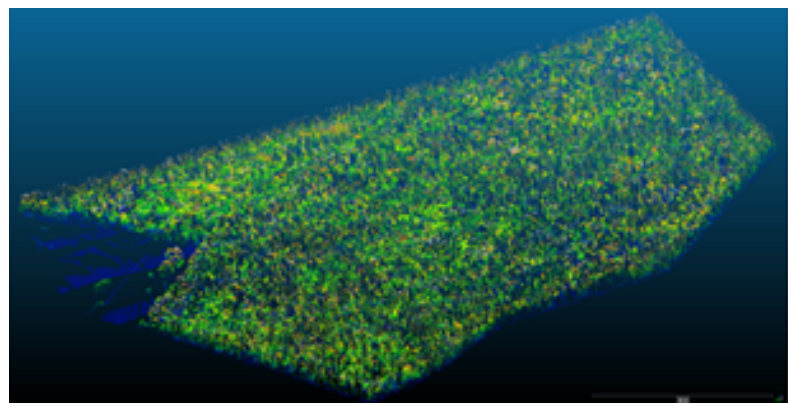

Figure 15: Elevated surface fuel at $0.40 \mathrm{~m}$ resolution

Figure 15 shows the elevated surface fuel visualised using CloudCompare at resolution $0.40 \mathrm{~m}$ and Figure 16 shows the vegetation in the near-surface fuel level across the entire site.

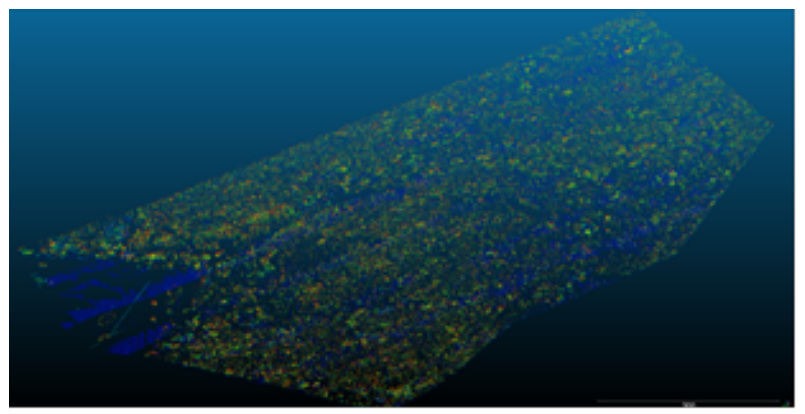

Figure 16: Near-surface fuel at resolution $0.40 \mathrm{~m}$.

These data can now be analysed and plotted to reveal plan coverage density and distribution information.

\subsection{Estimation of fuel coverage for elevated and near- surface fuel}

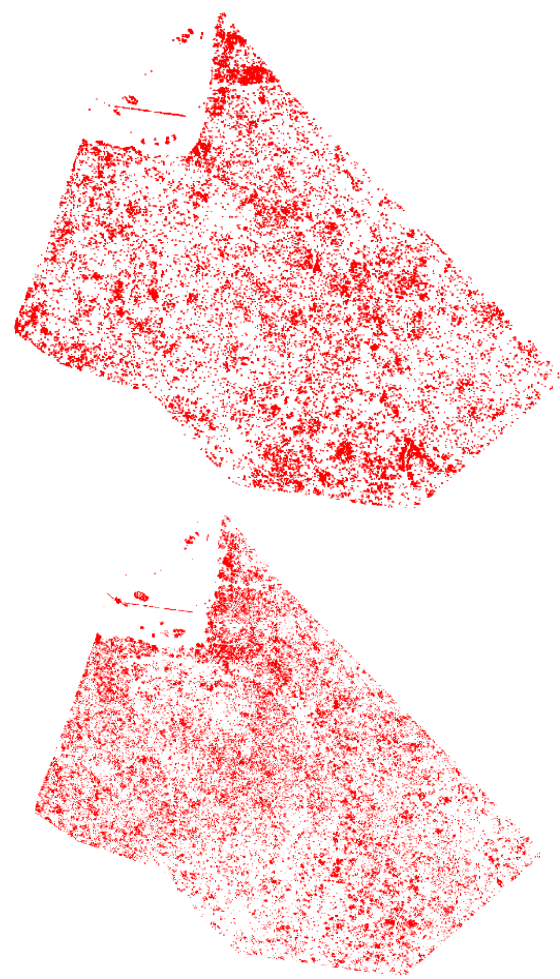

Figure 17: $0.40 \mathrm{~m}$ resolution voxel plots, where voxels do/do not contain near-surface fuel (above) and elevated fuel (below).
Figure 17 shows the extracted and isolated structural layers of concern to HR burn practitioners. The non-empty voxels containing are plotted in red and the white areas represent empty voxels (with no LiDAR points). The density and distribution of the fuel can be assessed even visually.

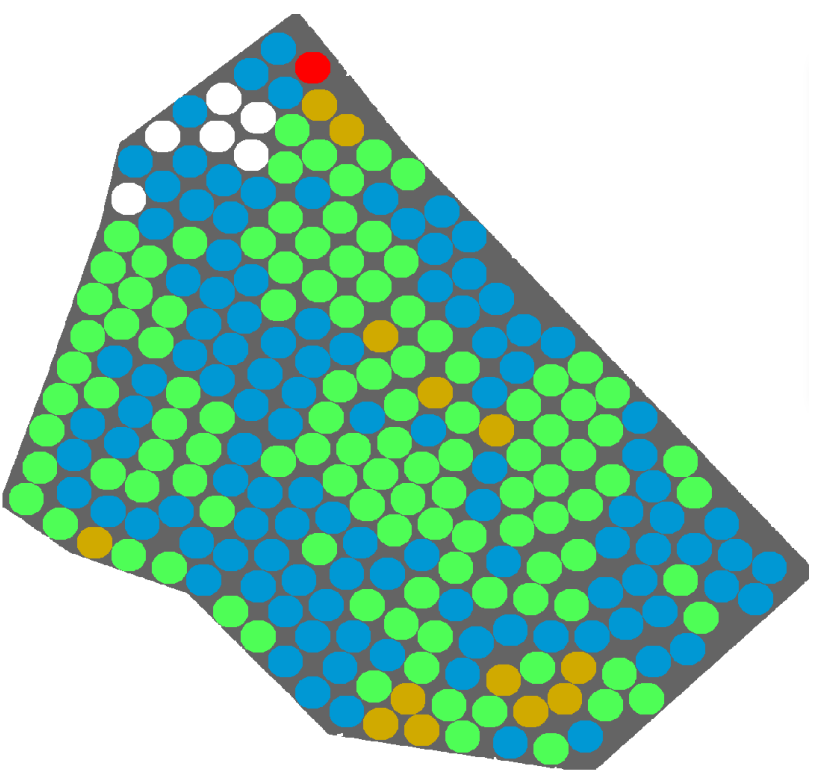

Figure 18: Densities of fuel types in circular areas with $10 \mathrm{~m}$ radius of near-surface fuel.

Figure 18 and Figure 19 illustrate circular areas having a radius of $10 \mathrm{~m}$, similar to the NSW knee-hip-shoulder methodology and the corresponding coverage percentages: $0-20 \%$ (blue), $20-40 \%$ (green), 40-60\% (orange) and more than 60\% (red).

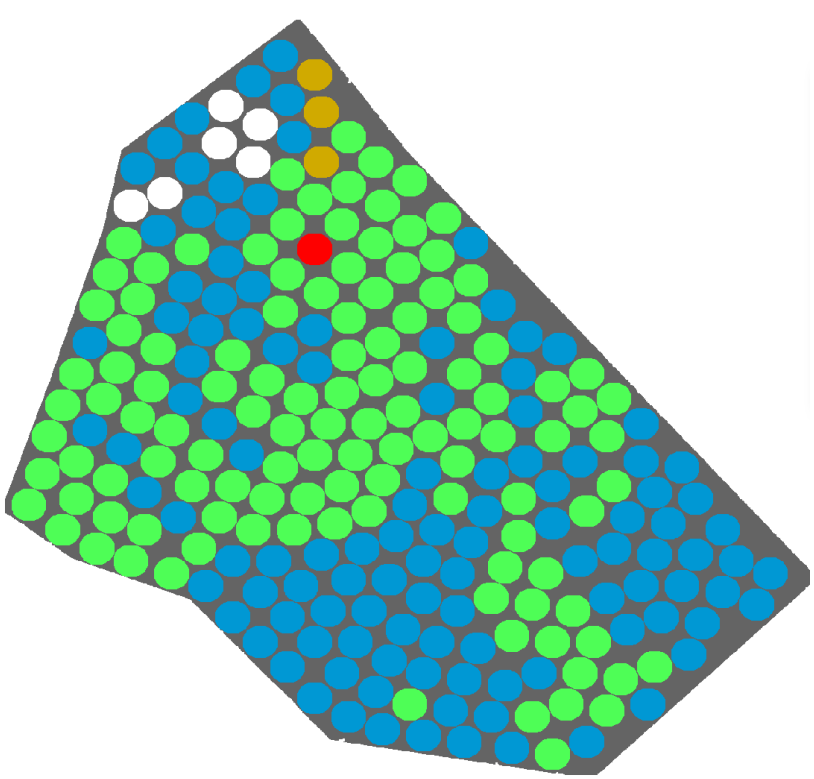

Figure 19: Densities of fuel types in circular areas with $10 \mathrm{~m}$ radius of elevated fuel.

The circular areas shown in the figures can readily be used by practitioners using OFHAG guide. For example. Blue areas indicate plan coverage less than $20 \%$. Based on the amount of near-surface and elevated fuel, these areas do not require HR 
burning. The other areas represent plant coverage greater than $20 \%$. These areas have to be checked and qualified for HR burning. At this point, a visiting fire practitioner can arrive at the site pre-prepared to ground truth the data and inspect the areas indicating the highest risk, and possibly direct any burns away from the blue zones.

To assess the research finding the test area was visited and the vegetation fuel was visually inspected. The observations confirmed the results obtained for elevated fuel. The images in Figure 20 illustrate vegetation in areas, which have high (red area in Figure 19) and low vegetation coverage (blue area nearby). The classification of near-surface fuel needs more investigation and it is too early to draw conclusions. Near-surface fuel is highly correlated to the elevated fuel and the tree canopy. If the canopy or elevated vegetation are dense, the near-surface vegetation is considerably less.
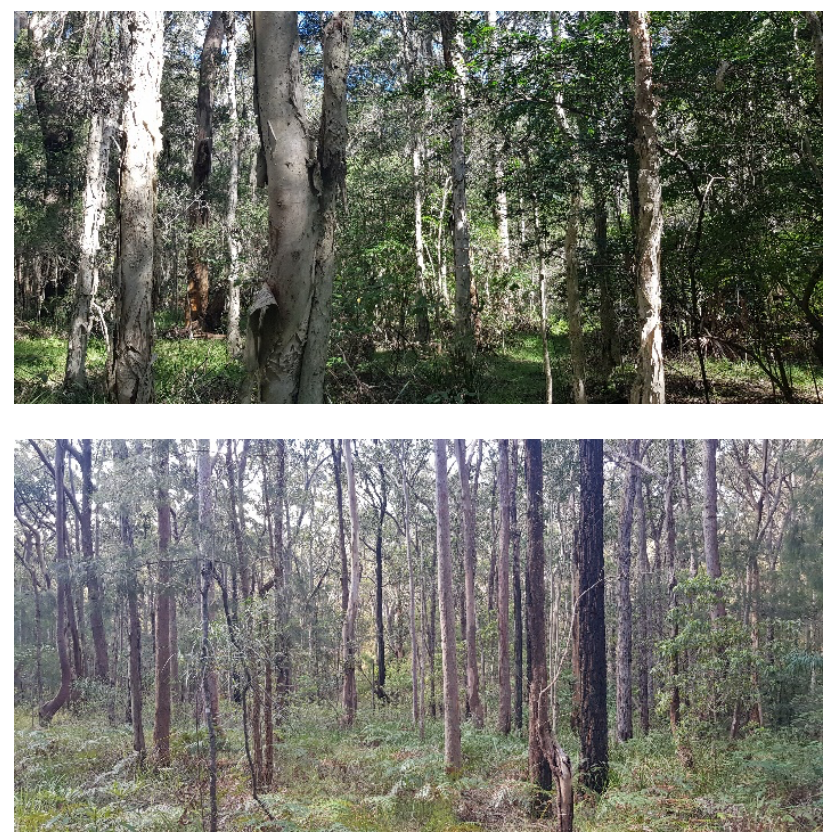

Figure 20: Images from the test site for elevation fuel: more than $30 \%$ coverage (above) and less than $20 \%$ coverage (below).

\section{CONCLUSIONS AND FUTURE WORK}

UAV drones and LiDAR pointclouds have become practically ubiquitous, and a represent a bigdata resource. The use of voxels, as demonstrated in this paper has enabled a substantial value-add to increase the interpretability, (re)usability and practical application. The workflow developed is low-cost, processor efficient and fit for the purpose of serving as a decision-support tool to support fire practitioners by improving the currency of data and in developing an evidence-base for helping map and prioritise the large-scale operation of HR burning. It should be noted that this research is still work in progress, but the results are very promising. The next steps will focus on ground-truthing and calibrating the voxel analysis method, specifically improving the terrain estimates and near-surface fuel. Further advancements in the include incorporating further sources of information into the model; particularly topographic and slope information that had not been examined in this study.

Given the window of opportunity to execute HR burns is contracting dues to climatic changes, it is important fire practitioners have up-to-date and longitudinal intelligence to best plan and perform the complex operations at hand.

\section{REFERENCES}

Almeida, D., Nelson, B., Schietti, J., Gorgens, E., Resende, A., Stark, S., 2016. Contrasting fire damage and fire susceptibility between seasonally flooded forest and upland forest in the Central Amazon using portable profiling LiDAR. Remote Sensing of Environment. 184, 153 - 160.

Chang, C., 2020. How the 2019 Australian bushfire season compares to other fire disasters. URL: https://www.news.com.au/technology/environment/how-the2019-australian-bushfire-season-compares-to-other-firedisasters/news-story/7924ce9c58b5d2f435d0ed73ffe 34174

Chen, Y., Zhu, X., Yebra, M., Harris, S., Tapper, N., 2017. Development of a predictive model for estimating forest surface fuel load in Australian eucalypt forests with LiDAR data. Environmental Modelling \& Software. 97,61-71.

Cheney, N.P., Gould, J.S., Catchpole, W.R., 1998. Prediction of fire spread in grasslands. International Journal of Wildland Fire 8, 1-13.

Cruz, M.G., Gould, J.S., Alexander, M.E., Sullivan, A.L., McCaw, W.L., Matthews, S., 2015a. Empirical-based models for predicting head-fire rate of spread in Australian fuel types. Australian Forestry. 78, 118-158.

Cruz, M.G., Gould, J.S., Kidnie, S., Bessell, R., Nichols, D., Slijepcevic, A., 2015b. Effects of curing on grassfires. II: effect of grass senescence on the rate of fire spread. International Journal of Wildland Fire 24, 838-848.

Forestry Commission of Tasmania, Tasmania Fire Service, 1984: Guideline for fuel reduction burning under dry forests. Forestry Commission of Tasmania, Hobart.

Gorte, B. Zlatanova, S., 2016, Rasterization and voxelization of 2D and 3D space partitioning. Int. Arch. Photogramm. Remote Sens. Spatial Inf. Sci., XLI-B4, 283-288. doi.org/10.5194/isprsarchives-XLI-B4-283-2016.

Gorte, B. and Winterhalder, D., 2004, Reconstruction of laserscanned trees using filter operations in the 3D raster domain, Int. Arch. Photogramm. Remote Sens. Spatial Inf. Sci., XXXVI-8 W2, 6p.

Gould, J. S., Cruz. M., 2012. Australian Fuel Classification: Stage II. Report number: EP126505.

González-Olabarria, J.R., Rodríguez, F., Fernández-Landa, A., Mola-Yudego, B., 2012. Mapping fire risk in the Model Forest of Urbio'n (Spain) based on airborne LiDAR measurements. Forest Ecology and Management. 282, 149-156. doi:10.1016/J.FORECO.2012.06.056

Grau, E., Durrieu, S., Fournier, R., Philippe, G. J., Yin, T., 2017. Estimation of 3D vegetation density with Terrestrial Laser Scanning data using voxels. A sensitivity analysis of influencing parameters. Remote Sens.Env., 188, 373-388. doi.org/10.1016/j.rse.2017.01.032.

Inan, M., Bilci, E., Akay. A.E., 2017. Using Airborne Lidar Data For Assessment Of Forest Fire Fuel Load Potential. ISPRS 
Annals of Photogrammetry, Remote Sensing and Spatial Information Sciences IV-4/W4: 255-258.

Handmer, J., Ladds, M., Magee, L., 2018. Updating the costs of disasters in Australia. Australian Journal of Emergency Management., AJEM 33 (2)

Hennessy, K., C. Lucas, N. Nicholls, J. Bathols, R., Suppiah, Ricketts, J., 2005. Climate change impacts on fire-weather in south-east Australia. Consultancy report for the New South Wales Greenhouse $\quad$ Office. http://www.cmar.csiro.au/eprint/open/hennessykj_2005b.pdf.

Hermosilla, T., Ruiz, L.A., Kazakova, A.N., Coops, N.C., 2014. Estimation of forest structure and canopy fuel parameters from small-footprint full-waveform LiDAR data. International Journal of Wildland Fire. 23(2): 224-233.

Hines, F., Tolhurst, K. G., Wilson, A., McCarthy, G. J., 2010. Overall Fuel Assessment Guide. Department of Sustainability and Environment. Fire and Adaptive Management, Report Number 82., 4th Edition. ISBN 978-1-74242-677-8.

Eusuf, M., Barton, J., Gorte, B., Zlatanova, S., 2020. Volume estimation of fuel load for hazard reduction burning: a voxel approach, Int. Arch. Photogramm. Remote Sens. Spatial Inf. Sci. XLIII-B3-2020. 1199-1206.

Listopad, C.M., Drake, J.B., Masters, R.E., Weishampel, J.F., 2011. Portable and airborne small footprint LiDAR: forest canopy structure estimation of fire managed plots. Remote Sensing. 3, 1284-1307. doi:10.3390/RS3071284

Mallet, C., Bretar, F., 2009. Full-waveform topographic LiDAR: state-of-the art. ISPRS Journal of Photogrammetry and Remote Sensing 64, 1-16. doi:

10.1016/J.ISPRSJPRS.2008.09.007

Morton, A., Graham, R., 2020. Almost 3 billion animals affected by Australian bushfires, report shows. The Guardian. URL:https://www.theguardian.com/environment/2020/jul/28/al most-3-billion-animals-affected-by-australian-megafires-reportshows-aoe

Penman, T., Christie, F., Andersen, A., Bradstock, R., Cary, J., G., Henderson, M., Price, O., Tran, C., Wardle, G., Williams, R., J., York, A., 2011. Prescribed burning: How can it work to conserve the things we value? International Journal of Wildland Fire. 20. 721-733. doi.org/10.1071/wf09131.

Pfeifer, N., Gorte, B., Oude Elberink, S., 2004, Influences of vegetation on laser altimetry-analysis and correction approaches, Int. Arch. Photogramm. Remote Sens. Spatial Inf.Sci., XXXVI-8 W2, 283-288

Price, O. and C. Gordon, 2016. The potential for LiDAR technology to map fire fuel hazard over large areas of Australian forest. Journal of Environmental Management, 181. doi.org/10.1016/j.jenvman.2016.08.042

Skowronski, N., Clark, L. K., Duveneck, M., Hom, J. 2011. Three-dimensional canopy fuel loading predicted using upward and downward sensing LiDAR systems. Remote Sens. Env., 112(2),703-714. doi.org/10.1016/j.rse.2010.10.012.

Sikkink, P. G., Keane, Robert E., 2008. A comparison of five sampling techniques to estimate surface fuel loading in montane forests. Int. Journal of Wildland Fire.,17(3), 363 -379. doi.org/10.1071/WF07003

Sidhaarthan, A., Bhuvaneshwari, B., Jayanth, N. 2012. Real Time Exact 3D Modelling of Objects from 2D Images using Voxelisation. International Journal of Computer Applications., 42, 20-24. doi.org/10.5120/5720-7781

Spits, C., Wallace, L., Reinke, K., 2017. Investigating Surface and Near-Surface Bushfire Fuel Attributes: A Comparison between Visual Assessments and Image-Based Point Clouds. Sensors (Basel, $\quad$ Switzerland), $17(4), \quad 910$. doi.org/10.3390/s17040910

Steffen, W., Hughes, L., Mullins, G., Bambrick, H., Dean, A., Rice, M., 2019. Dangerous Summer: Escalating bushfire heat and drought risk. Climate Council of Australia Limited. ISBN: 9780-6486793-9-4 (digital)

Thies, M., Pfeifer, N., Winterhalder, D., Gorte, B, 2004. Threedimensional reconstruction of stems for assessment of taper, sweep and lean based on laser scanning of standing trees, Scandinavian Journal of Forest Research 19 (6), 571-581

Tolhurst, K., Shields, Brett, Chong, Derek., 2008. Phoenix: Development and application of a bushfire risk management tool. Australian Journal of Emergency Management. 23. 47-54.

Vigilante, T., Thornton, R., 2016. Bushfires 2: Managing landscapes. Australian Academy of Science https://www.science.org.au/curious/earth-

environment/bushfires-managing-landscapes.

Vernier, J. P., Reed, J., 2020. Satellites Provide Multiple Views of Australia Fires from the Same Day. disasters.nasa.gov.

Volkova, L., Andrew, S. L., Stephen R. H., Christopher J. W., 2016. Visual assessments of fuel loads are poorly related to destructively sampled fuel loads in eucalypt forests. Int. Journal. Wildland Fire. XXV, 1193-1201. doi.org/10.1071/WF15223

Volkova, L., Aparico, W., Weston, A., Christopher, J. 2019. Fire intensity effects on post-fire fuel recovery in Eucalyptus open forests of south-eastern Australia. Sci.Total Env., 667, 328 - 336. doi.org/10.1016/j.scitotenv.2019.03.226

Yebra, M., Marselis, S., Van, D. A., Cary G., Chen, Y., 2015. Using LiDAR for forest and fuel structure mapping: options, benefits, requirements and costs. Bushfire \& Natural Hazards $C R C$, Australia.

Zhou, Q., Robson, M., Pilesjo, P., 1998. On the ground estimation of vegetation cover in Australian rangelands. Int. Journal of Remote Sens., 19 (9), 1815-1820. doi.org/10.1080/014311698215261 